\title{
Noise Solver for Refurbishment Construction Site Design
}

\section{SIGRADI2018 TECHNOPOLITICAS \\ xxii congresso da sociedade iberoamericana de gráfica digital 22th conference of the iberoamerican society of digital graphics 07|08|09|novembro|2018 iau usp | são carlos | sp br}

\author{
Ugo Maria Coraglia \\ TU Wien | Austria | Sapienza University of Rome | Italy | ugomaria.coraglia@uniroma1.it \\ Gabriel Wurzer \\ TU Wien | Austria | wurzer@iemar.tuwien.ac.at
}

Antonio Fioravanti

Sapienza University of Rome | Italy | antonio.fioravanti@uniroma1.it

\begin{abstract}
The noise generated by the presence of a construction site within complex structure in operation (e.g. school, hospital) is a problem that too often is underestimated but that can generate problems of different nature, both concerning the health of the actors involved and regarding the performance of daily activities present within such structures (e.g. carrying out a lesson, a surgical procedure). The main aim of our tool is to highlight the impact of the noise generated by the construction site activities on these daily activities and to allow the simulation in real time of the viable solutions, thus arriving to find the one that is considered most suitable.
\end{abstract}

Keywords: Hospital refurbishment; Construction site design; Noise reduction; Simulation.

\section{INTRODUCTION}

The technique drives politics. As reported in the assertion of Technopolitics, "all technology is generated within cultural, economic and social fabrics, as well as has political aspects in its conformation and its use" (SIGraDi 2018) but in our case is to be understood as an optimization instead of a revolution.

Technopolitics are interpreted as conceptions that operate on useful things that contrast the mere use of new technologies.

The unexpected results challenge and contrast the dominant models with other models that emerge from the results of these technological applications. That is, it has often happened in History that a dominant class promotes technology; but that same technology once mature frees forces, energies and subjects (kept until then at the margins) that rewrite the relations of force among the dominant classes, almost always subverting them.

These are the so-called "Disruptive Technologies".

Nowadays a lot of complex buildings (e.g. hospitals, schools, police stations) need to be refurbished for improving building performance/ accomplishing new codes/ restructuring building parts (Zhang et al., 2013). The most difficult issue is that the standard daily activities in these buildings almost always cannot be interrupted. So that we can have concurrently standard activities and construction activities and the construction site is frequently inside the same building side by side working spaces where staff and other actors involved (e.g. doctors, patients, students are still working.
In these building refurbishments during (re)construction activities one of the main problems is the noise impact caused by construction activities, especially on patients and doctors in hospitals or on students and teachers in schools; this impact makes severe conditions to perform their usual activities with loud environment and lacking concentration.

The noise, such as environmental stress, has a significant impact on people both in terms of his health and his physical, mental and social well-being (D'Alessio, A. 2013). In fact, the effects of this exposure can be traced back to 3 different typologies: specific, in particular auditory, nonspecific, that is endocrine and psychological or psychosomatic type on target organs (e.g. an exposure of $65 / 70 \mathrm{dBA}$ of LAeq of $24 \mathrm{~h}$ is considered the minimum value from which it is possible to record an increase in the onset of problems affecting the cardio vascular system), and psychosocial, such as sleep disorder and interference on performance, efficiency, attention and learning (ANPA 2000).

The World Health Organization (WHO), recognising the risk due to the noise exposure, recommends a maximum noise level for hospital environments in the range of $45 \mathrm{~dB}$ (but not exceeding $80 \mathrm{~dB}$ which is the said maximum). Unfortunately, this level is exceeded every day, even in the order of $20 \mathrm{~dB}$, as confirmed by the measurements carried out in Austrian and Spanish hospitals (Castro et al., 2013). In Italy, according to the UNI 8199-1998 and UNI 81992016 standards, even lower exposure levels are used, requiring that the acceptable noise levels do not exceed, e.g., $30 \mathrm{~dB}$ for the hospital rooms e $40 \mathrm{~dB}$ for the visitor areas (Uguccioni, G. 2005), as reported in Table 1. 
Table 1: Noise limit for hospital environments

\begin{tabular}{|l|c|}
\multicolumn{1}{|c|}{ ENVIRONMENT } & NOIS E LIMIT \\
\hline Hos pital rooms & $30 \mathrm{~dB}(\mathrm{~A})$ \\
\hline Wards & $40 \mathrm{~dB}(\mathrm{~A})$ \\
\hline Operating theatres & $35 \mathrm{~dB}(\mathrm{~A})$ \\
\hline Connection zones & $40 \mathrm{~dB}(\mathrm{~A})$ \\
\hline V is itors area & $40 \mathrm{~dB}(\mathrm{~A})$ \\
\hline General service areas & $40 \mathrm{~dB}(\mathrm{~A})$ \\
\hline
\end{tabular}

The re-organization of the hospital for the presence of a construction site is a problem that should not be underestimated. The construction site staff, who usually occupy entire hospital spaces creating problems that can be defined as "boundaries" (e.g. a wall or a door are no longer elements of division between 2 spaces but become elements of division between the construction site and the hospital, each of which committed to manage their own side, many times also with regard to the isolation (e.g. noise, dust) autonomously (see Figure 1), in some cases is forced to having to share these spaces with the health care staff, e.g. the aisle can be divided by creating an aisle in the aisle, with consequent security problems (an hospital aisle is designed according to certain rules and dimensions) and the impact of noise (this space if not perfectly isolated can become the weak point).

It is no longer conceivable, with current technologies, the closure of an entire hospital, or one or several

departments of it, due to the presence of a construction site inside them because the presence of the latter must now be considered a constant with to live together, given the high demand and need for

- renewal of equipment;

- improvement of health and hospital services;

- refurbishment and redevelopment of the spaces that make up the hospital itself.

It is not possible an uncritical coexistence of the construction site activities with the daily activities of the hospital, because through the simulation models it is possible to optimize the management of the activities and spaces of the hospital that holds the construction site.

The fact that it is possible to make a hospital work even during the refurbish works, thus improving its efficiency, for a longer period of time (nowadays with good planning this period could cover the entire life cycle of the hospital), confirms the assumption that changing the technique changes the politics, in this case the politics inherent to the working and financial management of the hospital.
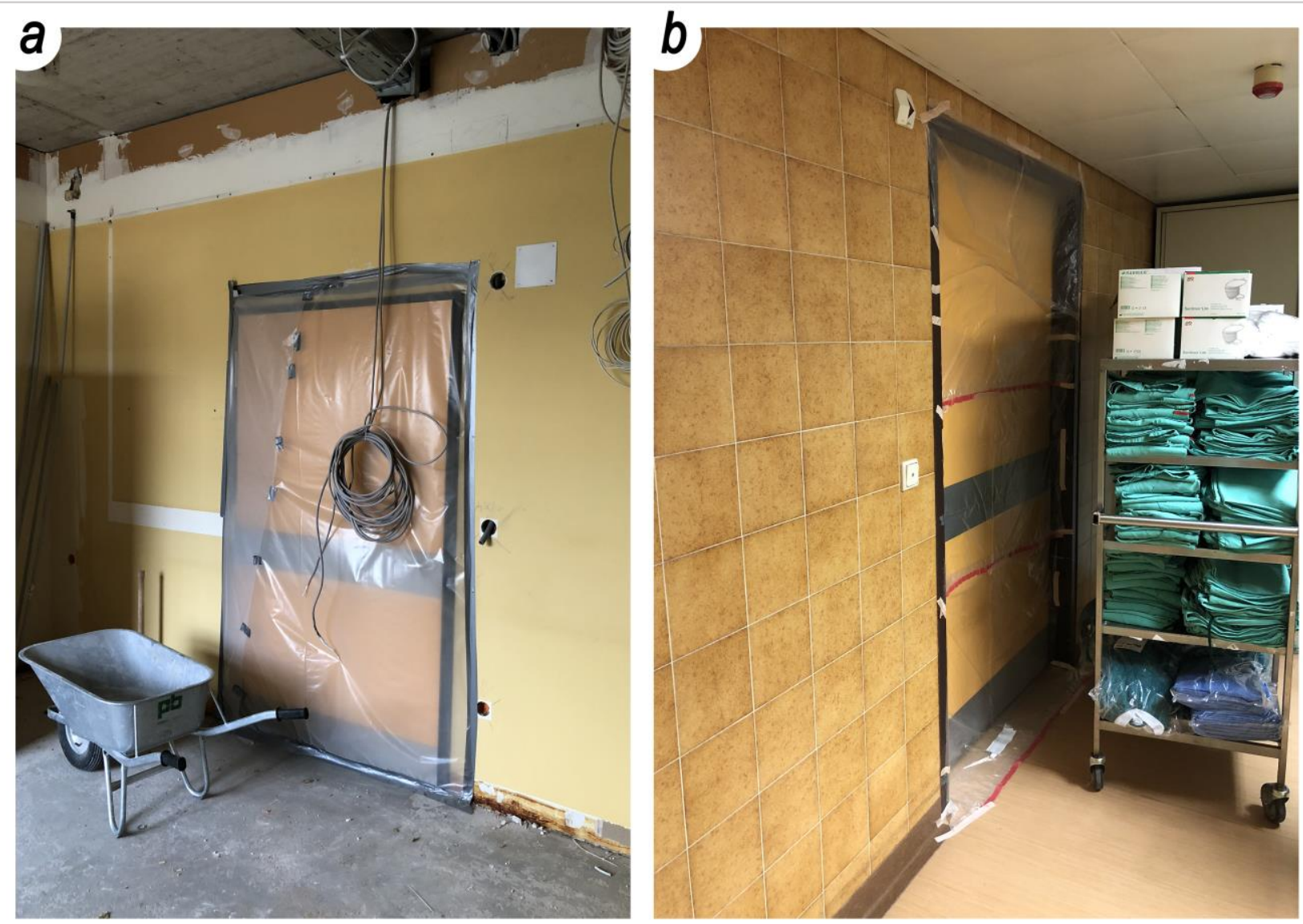

Figure 1: Landesklinikum Wiener Neustadt hospital a) construction site side, b) hospital side. Source: Authors. 


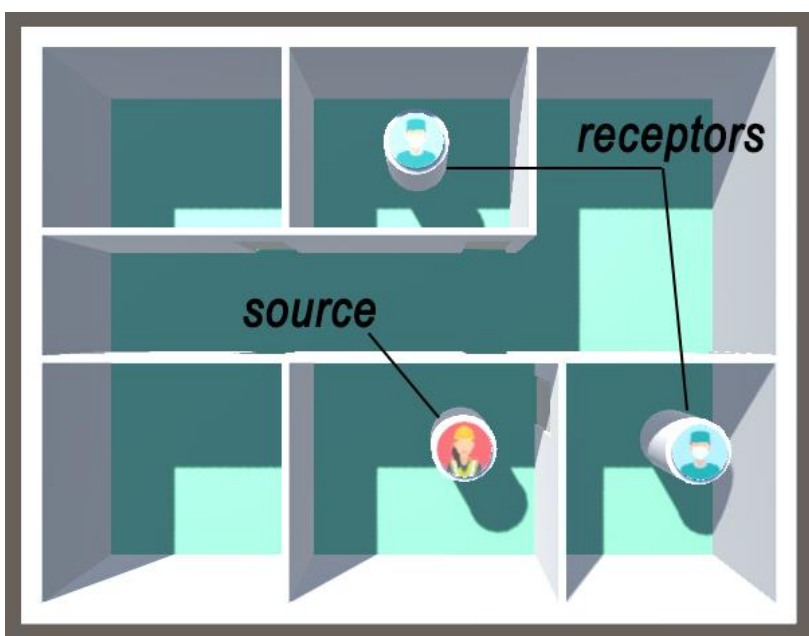

Figure 2: Definition and setting of sources and receptors. Source: Authors.

The paper will be focused on the noise impact inside a hospital during its refurbishment in a floor. This is a specific problem that can be seen from a higher abstraction layer as the more general issue of disturbing factors in a field.

\section{METHODOLOGY}

The main aim of our research is to support professionals from both sectors, management (e.g. hospital) and construction site, through an instrument that firstly highlights the impact of noise on daily activities caused by construction activities inside of the complex structure (e.g. hospital) and, secondly, it allows the designers to configure the best construction site project solution, that it is able to reduce the impact due to the noise without suspending the daily activities of the hospital, being able to modify and verify, iteratively and in time real, the effectiveness of their choices.

The proposed tool considers some steps of preparation of the context within which the simulation will take place.

1. Create or acquire the model in BIM (e.g. a hospital ward, a classroom of a school): through the use of BIM software, in our case Autodesk Revit, it is possible to structure the context of the examined environment and enrich the building components that compose it with specific information or factors (e.g. insulating);

2. Import the BIM model into a Game Engine (e.g. Unity3D): from Revit, the model is exported in FBX format, easily readable by Unity3D, environment in which it will be re-imported. Within this new model it will be possible, through the creation of specific algorithms, to simulate the noise and the admissible solutions to solve it;

3. Characterisation of the model in Unity3D: every characteristic, geometric or not, of building components of BIM enriched model has to be collected and managed by a database (e.g. Excel) for reconnecting within the Unity $3 \mathrm{D}$ model. This step can be done automatically setting Dynamo (Autodesk software) or manually. In both case, they represent the information structure of the scenario at the base of the final stage of simulation;

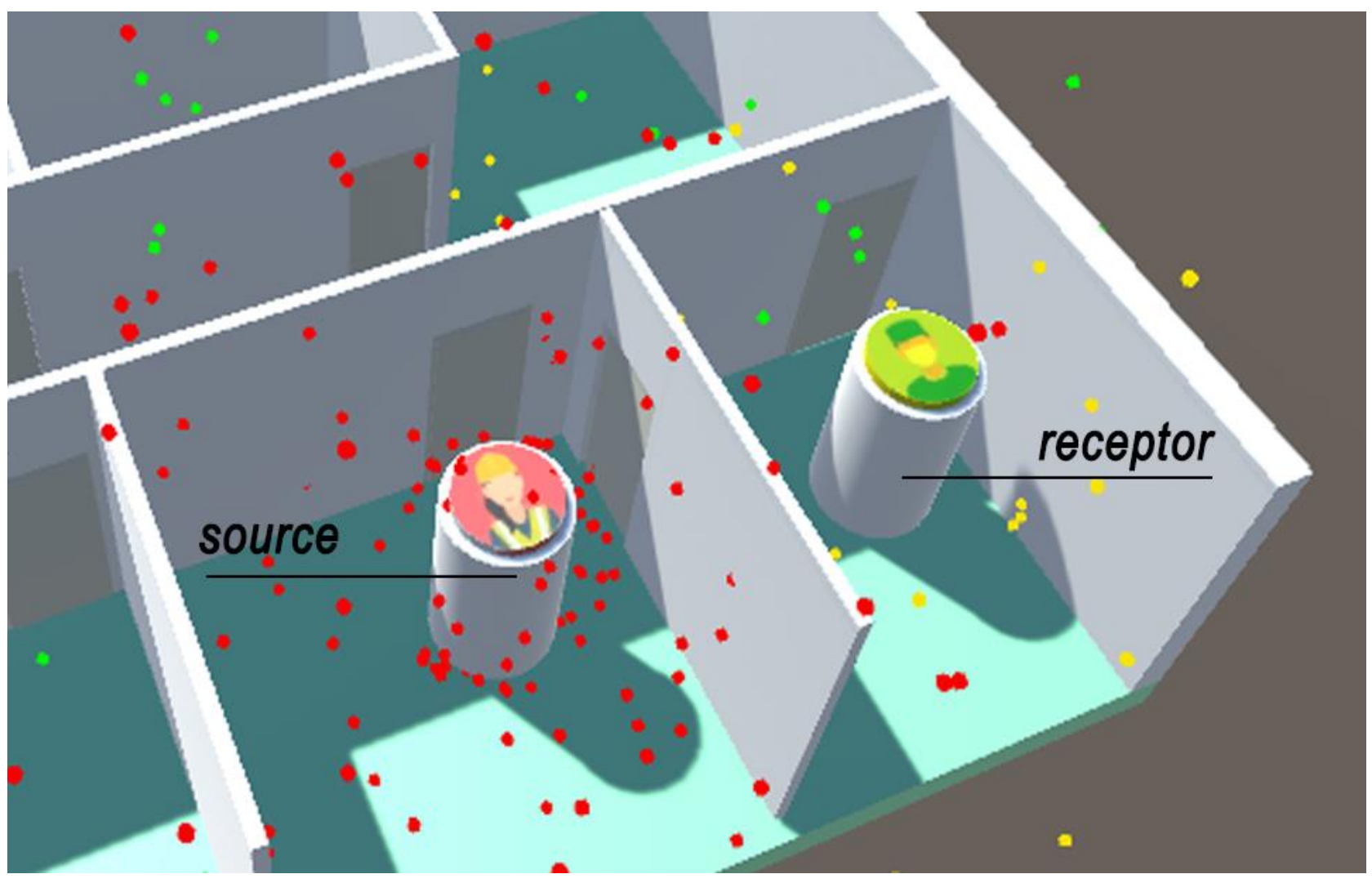

Figure 3: the receptor highlights the noise impact (Yellow means medium risk). Source: Authors. 

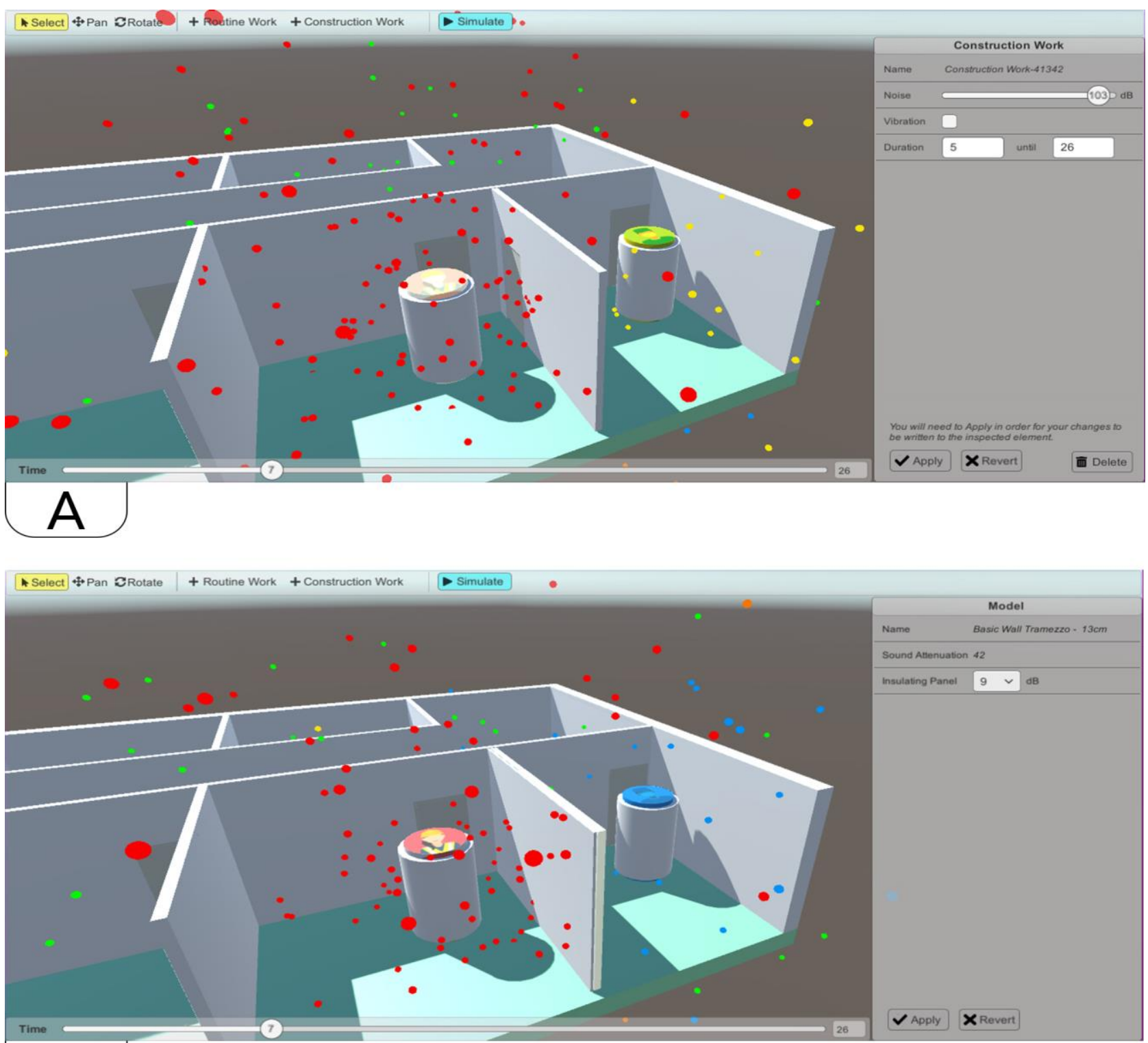

\section{B}

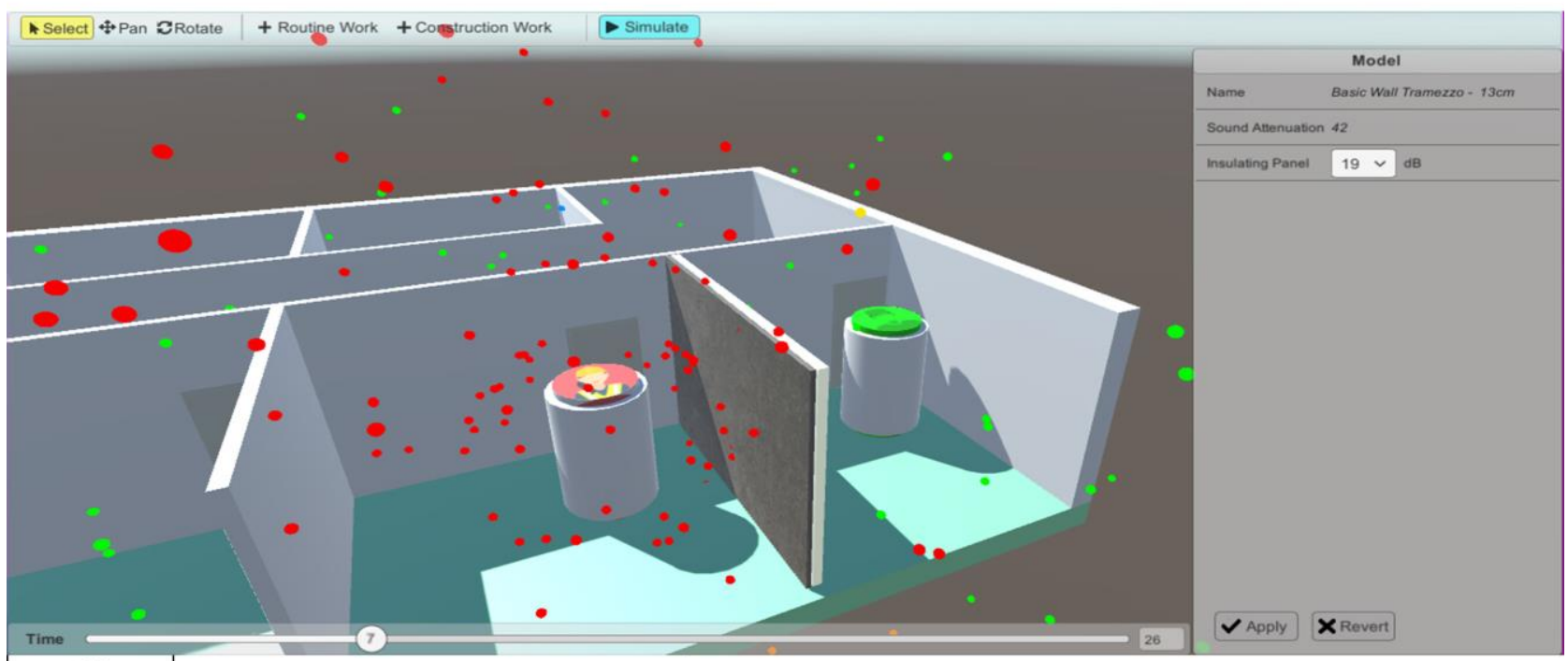

C

Figure 4: Situation without panel (A), situation in which different types of panel are applied with increasing insulation coefficients (B and C). Source: Authors. 
4. Definition and settings of noise sources (Castro et al., 2013) related to construction activities (see Figure 2). Within the Unity3D model, we can insert noise sources according to what is reported in the construction project, characterizing each one according to the sound level produced (e.g. sander $106,6 \mathrm{~dB}$, pneumatic drill 97,7dB (C.P.T. Torino)). The sound pressure level $[\mathrm{dB}]$ has been set according to the following formula:

$$
L_{2}=\left\{\begin{array}{lc}
L_{1} & \text { if } r_{2}<1 \\
L_{1}-\left|20 \cdot \log \frac{r_{1}}{r_{2}}\right| & \text { else }
\end{array}\right.
$$

This value undergoes a further decrease due to the impact/crossing through the building components (e.g. walls, doors).

NB: this simulation was made possible through the creation of a customized particle engine, as the use of one of those present by default within Unity3D would not have allowed to reach the results obtained.

5. Definition and setting of receptors (Castro et al., 2013) (see Figure 2): within the Unity3D model we can include daily hospital activities that work as receptors. Each of these receptors is set to visually highlight the impact through a colour coding from high risk (Red) to acceptable (Green) (see Figure 3);

6. Definition and setting of a noise reduction solve mechanism. Once the impact on the noise generated by the construction site has been ascertained, the designers can choose, in real time, the best solution for the case in question, intervening directly in the Unity3D model. Even if there is no mandatory order to follow, we could list the applicable solutions as follows:

- Closing/sealing the communication doors with the environment characterised by sensitive activities (this also entails advantages for the problem concerning the dispersion of powders), usually through the use of plastic sheets and adhesive tape;

- Changing the typology of door, choosing one with a higher insulating factor. This solution can also bring benefits in the long term, once the construction site has ceased to exist;

- $\quad$ Covering the dividing walls between two rooms with insulating panels. Inside the model it is possible to choose materials with different thicknesses and insulating factors (e.g. Piombarol of Thermak) pre-loaded in our tool or personalizing them (See Figure 4);

- Covering the connection doors between the environments involved, for the time necessary to complete the work, with panels of different thicknesses and insulating factors. This solution may have to provide for the opening of a door, temporary or not, on another wall.
7. Visualisation and, eventually, modifying of solution submitted by our tool. As already explained above, the professional once loaded the model inside Unity 3D will have the ability to freely operate and verify any solution, in real time, up to the solution that will be more suitable to solve the problems related to his project (See Figure 5).

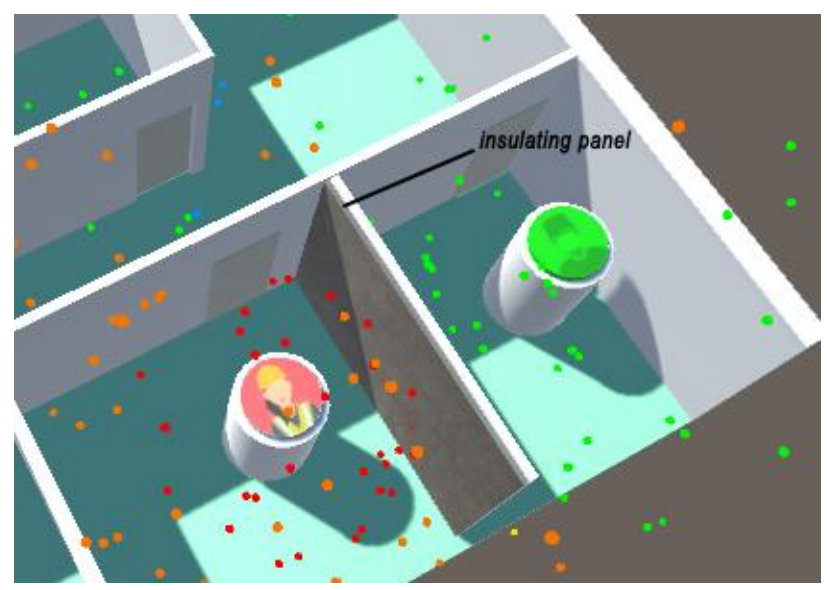

Figure 5: Visualisation of noise reduction (green means acceptable). Source: Authors.

\section{RESULTS}

Thank to visualisation and computational results in real time of different design solutions, professionals can choose different layouts of architectural design solutions according to different noise types and positions during the design phase of construction site activities to avoid suspending daily hospital activities.

From the point of view of the construction site, the correct choice of materials to reduce noise and their quantity during metric estimation allow a reduction in costs (e.g. being able to observe, thanks to the tool, the construction site activities in relation to the hospital ones it is possible to arrive at the conclusion of having to apply the highly performing insulating, and consequently more expensive, only on the walls in contact with the rooms occupied by sensitive activities) and time scale (e.g. an error in the design phase may lead to delays in final delivery some works). From the hospital staff's point of view, however, the possibility of viewing the areas occupied by the construction site in 3D and their impact on the surrounding areas and on the various actors involved can facilitate the correct management and the relative relocation of the daily activities inside of the single department, so as to safeguard the health of the patients and the continuity of operation of the hospital, with a consequent reduction in management costs.

\section{CONCLUSIONS}

The performance simulation, noise exposure evaluation and solver mechanism can help professionals in defining/designing construction site even during the early stage of design to rightly choose and select solutions to reduce noise impacts. This simulation has a general validity so that it can be applied in a more general field and also be adopted to deal with different issues such as dust or vibration ones in refurbishment sites. 
In future works, we will try to make our tool even more efficient and complete by going to consider the impacts related to vibration and dust and the related technical

\section{ACKNOWLEDGMENTS}

A special thanks to the Landesklinikum Wiener Neustadt hospital and to all of its staff for allowing us to visit the construction sites opened inside it and to have made possible the acquisition of data and photos.

\section{REFERENCES}

Zhang, S., Teizer, J., Lee, J.K., Eastman, C.M., and Venugopal, M. (2013), Building Information Modeling (BIM) and Safety: Automatic Safety Checking of Construction Models and Schedules, Automation in Construction, 29, pp. 183-195.

D'alessio, A., Midulla, G., (2013). Noise's effects on individual health. Prevention and Research in Medicine, 60, doi: 10.7362/2240-2594.147.2013
ANPA, (2000), Rassegna degli effetti derivanti dall'esposizione al rumore (http://www.arpa.veneto.it/temi-ambientali/agentifisici/file-e-allegati/AGF_2000_16.pdf)

Castro, D., Simões, H., Figureido, J.P., Tavares, Ó., Braga, H., Negrão, M,. Gonçalves, R., Bizarro, V., Ferreira, D., and Ferreira, A. (2013) Determination of noise level in the intensive care unit of Coimbra Hospital and University Center, International Symposium on Occupational Safety and Hygiene - SHO2013, Guimarães (Portugal), pp. 425-430.

UNI EN ISO 11690-1 : 1996, Acoustics - Recommended practice for the design of low-noise workplaces containing machinery Part 1: Noise control strategies.

Uguccioni, G. (2005), L'evoluzione della tecnologia impiantistica al servizio degli edifici ospedalieri', XXXII Convegno ANIMP OICE - UAMI, Rimini, pp. 33-34.

Database C.P.T. Torino (www.cpt.to.it) 